Article

\title{
Designing Buildings to Cope with Emergencies: Findings from Case Studies on Exit Preferences
}

\author{
Aysu Sagun ${ }^{1, *}$, Chimay J. Anumba ${ }^{2}$ and Dino Bouchlaghem ${ }^{3}$ \\ 1 Middle East Technical University, Northern Cyprus Campus, Kalkanlı, Güzelyurt, \\ Mersin10, Turkey \\ 2 Department of Architectural Engineering, The Pennsylvania State University, University Park, \\ PA 16802, USA; E-Mail: anumba@engr.psu.edu \\ 3 School of Architecture, Design and the Built Environment, Nottingham Trent University, \\ Nottingham NG1 4BU, UK; E-Mail: dino.bouchlaghem@ntu.ac.uk \\ * Author to whom correspondence should be addressed; E-Mail: saysu@metu.edu.tr; \\ Tel.: +90-392-661-2906.
}

Received: 12 April 2013; in revised form: 30 May 2013 / Accepted: 5 June 2013 /

Published: 18 June 2013

\begin{abstract}
Static information found in current building design guidance documents is not adequate to achieve efficient safety and security in public buildings during emergencies. There is a need to consider space characteristics and dynamic information related to building use, behavior and movement of users in various circumstances, as well as their interactions with each other and with their immediate environment. This paper explores the building design issues associated with safety and security and focuses on the exit preferences of building occupants during emergency evacuations. Exit preferences of users in public buildings were investigated using two types of case studies: Observation Case Studies (OCS) and Simulation Case Studies (SCS). The findings from the associated questionnaires and logistic analysis of the OCS data showed that "distance" and "familiarity" with the building were the two most important factors for exit preference in office buildings. It was also found that imbalanced use of exit doors considerably increases the evacuation time. Finally, further research study opportunities are discussed. SCS underscored the difference between evacuation assumptions in current building guidance compared with the results of real life experiments.
\end{abstract}

Keywords: building design information; evacuation design; emergency; exit preference; fire safety; evacuation modeling 


\section{Introduction}

The consequences of recent extreme events such as natural disasters and terrorist attacks have raised awareness of the importance of building design associated with safety and security. It has become clear that building design needs to broaden its focus on improving safety of the building occupants during extreme events in addition to construction system design, material use; heating, ventilation and air conditioning (HVAC) design, and layout and circulation design [1]. Minimizing the impacts of emergencies is not limited to minimizing the damage to the physical structure of the buildings. Safety of building occupants is the most vital point. Therefore safe building design needs to consider needs, requirements and the cognitive abilities of occupants related to vision, sound, heat and haptic senses because it is highly dependent on characteristics of the users and their interaction with the building. Even the occupants with special needs should be considered during building and evacuation design $[2,3]$. Within this context, the management of building occupants, sheltering and evacuation during emergency events are important. It is important to consider the design process as a whole to ensure a safe and secure building that:

- Controls building access;

- Prevents targeting occupants;

- Integrates visual and audio notifications;

- Enables efficient evacuation.

Such a design approach covers the three main areas of building layout and circulation design namely:

- Means of ingress;

- Circulation;

- Means of egress.

These design aspects need to be investigated and considered carefully with appropriate design information and guidelines to improve safety in the built environment. Considering and identifying hazard resistance methods for various natural and human-induced events should be an integral part of the design projects [4]. Evacuation modeling software simulate circulation and evacuation under different conditions and different behaviors of evacuees. Different design or environmental conditions can be created with evacuation modeling software (such as different building designs with different numbers of doors at different locations or simulation of fire at various locations). The recent developments in evacuation modeling software also enable the integration of various behaviors of people with changing characteristics or level of awareness such as simulation of populations with different/similar age groups, physical abilities and sex. The properties of the people, environmental factors and doors are modified to simulate these conditions and characteristics for the building simulations.

Previous research conducted at Loughborough University was focused on the modeling of crowd movement to improve the design of sport stadia and schools, and demonstrated the importance of capturing dynamic information related to crowd movement on the design of such spaces $[5,6]$. The research on which this paper is based is concerned with the design of buildings for the safety of users in emergency events and builds on the above work to establish the scope for enhancing safety through 
the improved design of the built environment to better cope with extreme events. It also seeks to study evacuations in order to develop new design guidelines to enhance the safety of occupants. The focus of the research presented here was on the exit preferences of building occupants. This paper summarizes the methodology and presents the findings from two case studies-Observation Case Studies (OCS) and Simulation Case Studies (SCS) — conducted on three office buildings. The use of computer assisted evacuation modeling to identify the differences between the assumptions in current building guidance and real life circumstances was highlighted via SCS.

\section{Building Design for the Safety of Users during Emergencies}

Inadequate built environment design and crowd management can lead to loss of life and injury in public spaces [7]. However, it is not possible to define the boundaries in building design because it depends on the context and the purpose of the design [8]. Human behaviors during building evacuation such as congestions, herding, panic, ignorance of guidance or variations in route and exit preferences based on the level of familiarity with the building are challenges to design a fixed guidance system for safe building design and they are effective issues to improve safety in buildings [9].

Moreover, it is not possible to consider and satisfy safety and security requirements of all types of extreme events for building design. However, as Glover [10] claimed, protection against an abnormal set of events can often provide a level of protection against some other sets of abnormal events. Fulfillment of building code requirements in the design process is not an assurance to efficient functioning in real life daily use and emergency situations [11]. Moreover, current building design guidance (codes, standards, etc.) include false assumptions on the behavior of people and present static building information that highlight only some of the safety issues. As such, they need to be revised to include the dynamic information that can guide designers in their design process by reflecting the real life circumstances. Observations of crowd dynamics during extreme events can provide clues about the failures found both in the design of the built environment and the management of venues and social events. Observation of occupant behavior during fire escape and application of fire safety measures can facilitate safety of building occupants during an extreme event. For instance dividing the building into compartments of manageable risks by isolating and limiting fire as a design strategy for fire safety can provide safe areas, routes and exits [4]. A logical and systematic way of defining possible safety problems and how to avoid them can improve building design to prevent catastrophes with severe consequences. Building occupants can have a significant influence on the design definition as the ones who use and interact with the space. In this context, building design requires a user-centered approach where user needs and safety issues are considered together with ergonomics and dimensional requirements.

Each person perceives the space, behaves, interacts and makes decisions for way finding, navigation or evacuation within his/her own perspective. Nguyen et al. [12] define behavior as the response to stimulation from the environment of the individual, group, or crowd. Understanding the behavior of individuals is essential before investigating and defining factors affecting crowd behavior and movement. The behavior of a person is characterized by his or her actions and reactions under specific circumstances. The behavior of groups may show different characteristics according to the interactions with the space and other people. In crowded public spaces, people are highly affected by one another's 
behavior. Moreover, the behavior of people during emergencies differs from that under normal conditions because new and unique situations arise in case of an emergency where previous actions and interactions will no longer work with other people and the physical environment $[13,14]$. Crowd management, as a systematic approach to control the behavior of large groups of people for safety and security, helps in the planning, organization, guidance and evaluation activities considering crowd dynamics.

Crowd management can benefit from research on crowd characteristics related to behavior in order to develop guidance for fast and effective evacuation processes. The four interacting elements that need to be considered to minimize injuries and death during crowd situations are defined as: time, space, information, and energy [15]. Fruin defined time as the crowding period; space as the size and layout of the occupied area; information as the perceptions of the people in the crowd to take some group action; and energy as the pressures created by the mass of people that can cause accidents and death. Within this context, crowd management considers the facility, size, and behavior of the crowd, means and routes of entrance and exits, communication, jamming and queuing.

The fundamental principle for safety in buildings is to ensure that the occupants in a building are safe during emergency events as well as normal conditions. It is important to provide the opportunity for the occupants to move to a safe area, either inside or outside the building before the environment becomes hazardous. The design of the means of egress is defined by the number and location of exit routes and doors that ensure safe and continuous flow without any obstructions. Exit doors include both the doors used in natural conditions and the emergency exits used during an emergency event. The evacuation process is dependent on the performance of the exits. This refers to how well the exits enable speedy evacuations by facilitating the efficient flow of people. It is influenced by a number of factors related to the characteristics of both the building and the building occupants. These can be summarized as:

- People flow rate;

- Door dimensions;

- Visibility of the exits;

- Door condition (open or closed);

- Building geometry;

- Obstacles on the way to exits (furniture, columns, etc.);

- Circulation routes;

- Signage.

People heavily rely on their own personal experiences in decision making. As Benthorn and Frantzich [16] stated, people's behavior is related to the schemata in their mind that maps how different facilities are organized in specific situations. This prior knowledge and instant perceptions merge to help them to make decisions when they face an unexpected event. In case of an emergency, they have to choose their exit route and door to leave the area that is exposed to danger. People's exit choice depends on the following factors [17-19]:

- Familiarity with the exit door;

- Distance to the exit;

- Visibility of the exit door; 
- Signage;

- Movement of other people;

- Orientation of the fire marshals;

- Obstacles on the exit route;

- Queuing in front of the doors.

The design of buildings can be improved to mitigate the impacts of emergencies on people if these factors are investigated in detail to develop guidelines for design solutions for different types of buildings, circumstances and emergency events. Over-reliance on standards may limit the designers' ability to fully express their design ideas or develop better design solutions for particular cases. It can also dissuade them from searching and developing a deeper understanding of safety issues that may be specific to their design. This over-reliance may also create a danger by limiting their responsibility, causing inefficiency by letting them avoid some design issues because they are not stated in standards or codes of practice [8].

\section{Research}

\subsection{Research Approach}

This research was designed to investigate the building design issues to improve the safety of occupants during emergency events. The related objectives are to:

- Review requirements and procedures for crowd safety during emergencies, and current relevant building design information, guidelines and standards;

- Review people flow simulation tools and techniques to establish their suitability for use within the context of crowd modelling for emergency events;

- Customise a suitable evacuation modelling software and conduct scenario-based case studies;

- Define guidelines that specify improved designs that ensure better safety of users during emergency events within large public spaces.

Within this context, the mitigation of the impacts of terrorist attacks was investigated with a focus on the building evacuation processes. The main methods used in the research include: an extensive literature review for background information on safety, crowd behavior and building design issues associated with terrorist attacks and other emergencies; interviews with safety, security and building design experts; observation of crowd behavior, movement and evacuation patterns during real fire evacuation tests using video recorders and questionnaires; and computer modeling and simulations of evacuations using a evacuation modeling software. Figure 1 illustrates the stages of the study in detail. 
Figure 1. Research methodology.

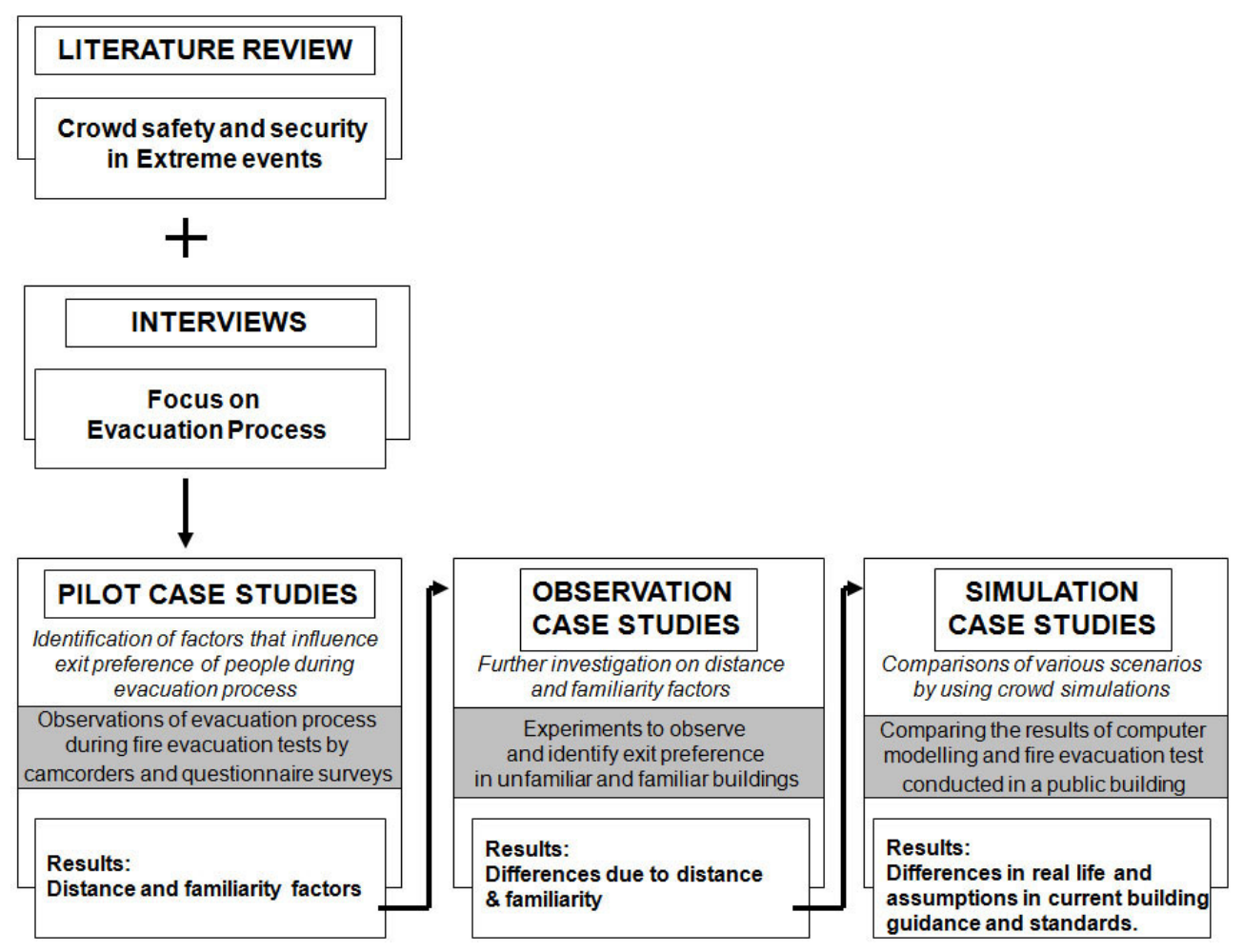

\subsection{The Case Studies}

\subsubsection{Observation Case Studies (OCS)}

The purpose of the observation case studies (OCS) was to observe people's exit choices during evacuations in office buildings. The objectives were to:

- Identify exit preferences during evacuations;

- Observe behavior during emergency events (in this case, a fire alarm);

- Identify the factors affecting the exit choice;

- Observe the evacuation time and factors that affects the evacuation time.

Two pilot OCS were conducted in public buildings at the Loughborough University campus before the main case studies. These pilot case studies identified and eliminated the deficiencies in management of the evacuation drills (such as location of cameras, defining the number of people to assist during the drill, etc.) to properly design the main OCS. The main OCS was conducted to collect data on the exit preferences of people in three office buildings with similar characteristics.

The OCS were conducted in the Research Hub of the School of Civil and Building Engineering at Loughborough University, office buildings of the consulting firm, Buro Happold, in Leeds and Glasgow. All OCS buildings had an open plan layout and more than one exit (3, 4, 2, respectively) to offer choices for the building occupants during the evacuation process. One of the exits was the main door used for entering and leaving the building in everyday use in each building and this door was assigned to be the familiar door for the case study analysis. The buildings were observed during annual fire evacuation drills using digital video recorders to capture people's exit choices, their reactions when they first heard the alarm and the bottlenecks that occurred in or near the exits (Figure 2). The 
locations of the cameras were identified such that the flow of people to the exits in the whole space could be observed rather than just the exits. The occupants of the buildings were not informed about the fire drill. The evacuation drills were conducted in the afternoon during clear weather conditions. The number of people using each exit door was determined using tally counters during the evacuation drills to identify the popular exit preferences. The number of occupants that participated in the fire evacuation drills were 41, 97 and 86, respectively. Finally, a questionnaire was distributed to all evacuees to identify:

- Location of people in the building;

- Exit choices;

- Reasons for preferences;

- Visibility and clarity of signs;

- Orientation of people by the fire marshals.

Figure 2. A snapshot from Observation Case Study (OCS) 1.

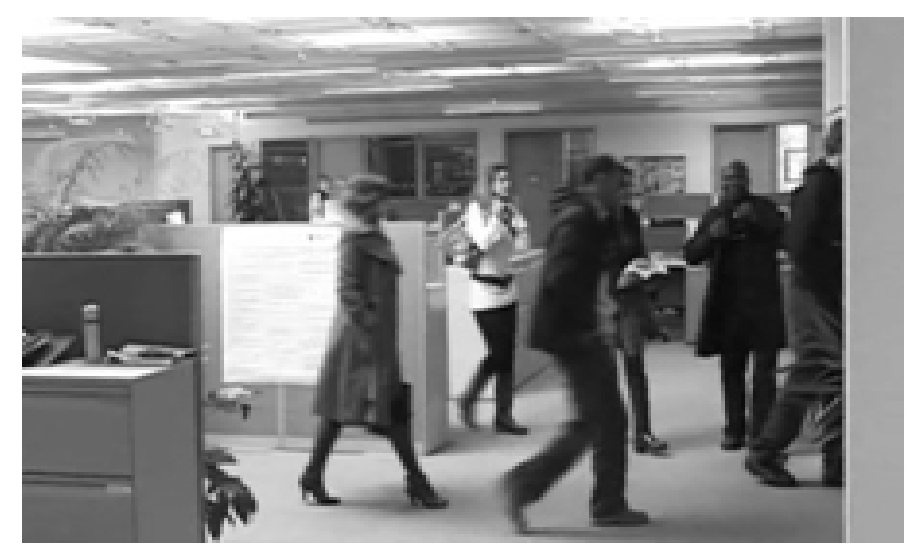

In all OCS, the fire marshals played their role to reflect the situation that would occur during a real emergency case. It was anticipated and was supported by the results of the questionnaires that they did not have an influence on exit preference but on the pre-movement time; the time between the alarm and first movement to the exit doors. The only problem during the OCS was the low number of people responding to the questionnaires. Less than $70 \%$ of participants responded to the questionnaire. More responses from the evacuees would have given more dependable results.

\subsubsection{Simulation Case Studies (SCS)}

The Simulation Case Studies (SCS) were conducted to test various evacuation scenarios for the office buildings used in OCS. The purpose of the SCS was to investigate how the factors identified in OCS affect the evacuation and design process using evacuation modeling techniques. The objectives were to:

- Identify and validate the critical building design parameters that are important during emergency evacuations;

- Identify the changes required to building design guidelines and standards to improve the safety of users in emergencies; 
- Identify the effect of exit choice on evacuation time.

The exit doors were not used equally in the OCS, there was a tendency to use the familiar door and this raised the question of how the evacuation time would change if the design of the building led people to use more doors. Each building was modeled after each OCS using building EXODUS-a evacuation modeling software developed by the Fire Safety Engineering Group at Greenwich University to simulate people-people, people-fire and people-structure interactions (Figure 3) [20,21]. It was used because it has a user friendly interface and it can import DXF files, which contain the geometry of the buildings. Moreover, it enables the user to create various scenarios by making changes to the properties of the people (sex, age, etc.), the speed of their movement in both horizontal and vertical flow, and the properties of exits (open, closed, main, alternative, etc.). However, more advanced visualization and faster rendering properties would have improved the quality of the simulation with building EXODUS.

Figure 3. 3D Representation of the Simulation Case Study (SCS) 1.

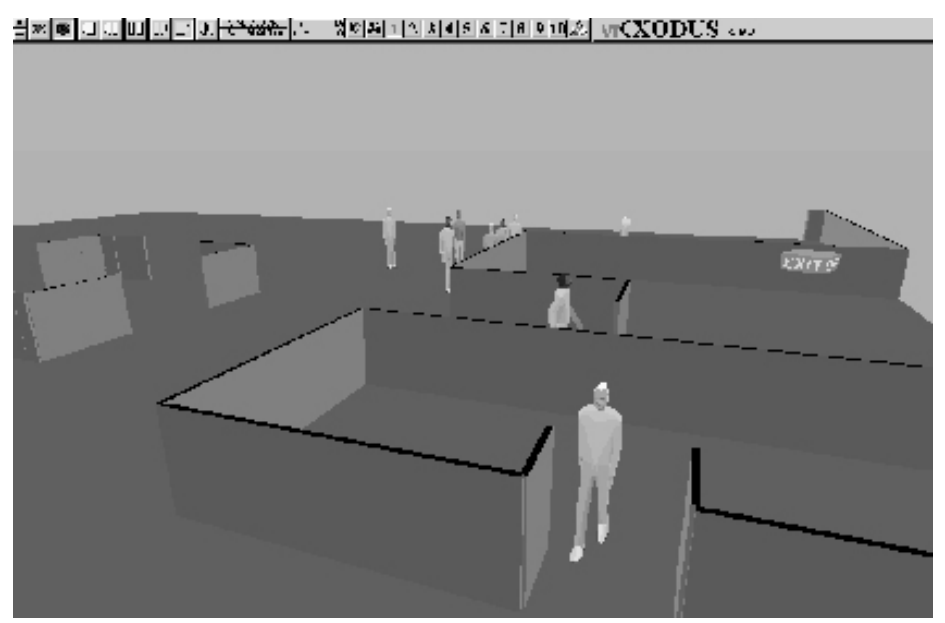

The evacuation simulations of each building tested various scenarios where the use of familiar (main) door and alternative exit doors were different. The properties of the doors were also changed according to the simulation scenarios as follows:

Scenario 1: The main door was closed but all other alternative exits were open

Scenario 2: All the doors were active and open;

Scenario 3: All alternative doors were closed and only the main door was open.

\section{Analysis of the Results}

The analysis of the pilot OCS questionnaires showed that the most important factors affecting the exit preference are "familiarity with the exits" $(14 \%-18 \%)$ and the "perceived distance to the exits" $(51 \%-57 \%)$. The results of the main OCS were in line with these findings and the main case study data enabled a more comprehensive analysis under the following three headings:

- Analysis of the OCS questionnaires;

- Logistic Regression Analysis of the data from OCS;

- Findings from Simulation Case Studies. 


\subsection{Analysis of the Questionnaires}

The first OCS was conducted in an open plan office with a square geometry. Three doors were located at the mid points of three sides of the square. The second OCS was conducted in a two storey open plan office building. The building also had a mezzanine floor which was connected to the main floor with two staircases. There were four staircases leading from the main floor to the outside: one main entrance door, one secondary door at the front of the building and two emergency exits at the rear of the building. The third OCS was conducted in a two storey open plan office building that has two mezzanine floors. There were two exits from the building: one main entrance door and one emergency exit at the cross end of the building. The responses to the questionnaires in the three OCS are presented below.

\subsubsection{Familiarity with the Emergency Exits}

The results of the questionnaires revealed that almost all of the building occupants were familiar with the emergency exits. Only a few respondents indicated that they were not aware of the existence of emergency exits in OCS $1(16 \%)$ and OCS 2 (4\%) (Figure 4).

Figure 4. Familiarity with the emergency exits.

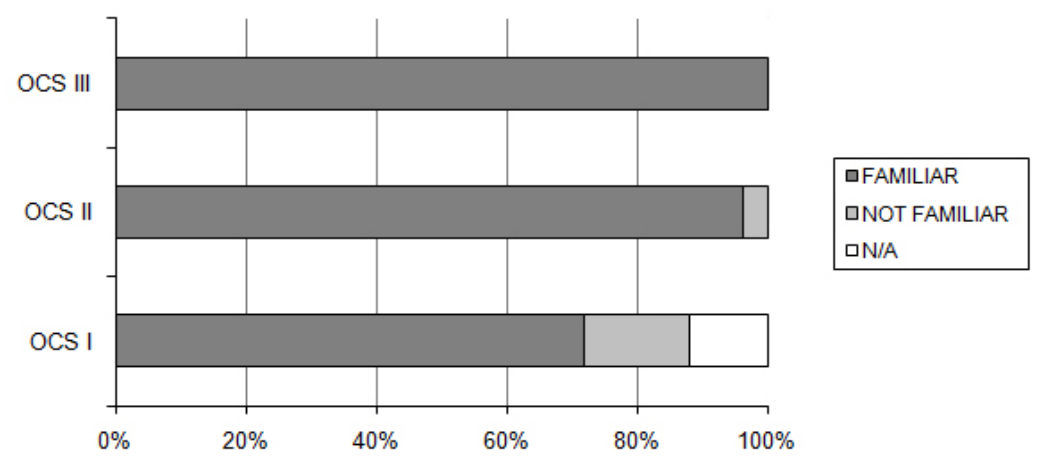

\subsubsection{Awareness of the Emergency Signs}

Most of the respondents were aware of the emergency signs in the building in all the OCS buildings and indicated that the emergency signs were clear. Figure 5 illustrates the percentages and response levels.

\subsubsection{Orientation by the Fire Marshals}

The fire marshals played their role during the fire evacuation tests in order to reflect the conditions in a real emergency situation. They warned people about the emergency and asked them to leave the building. More than $80 \%$ of the respondents indicated that they were not oriented to a specific door by the fire marshals in all case studies (Figure 6). 
Figure 5. Clarity of the emergency signs.

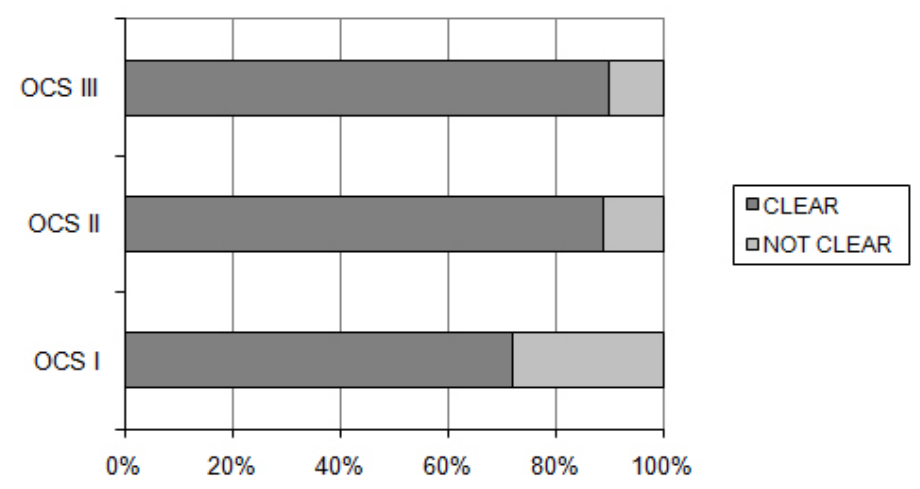

Figure 6. Orientation by the fire marshals.

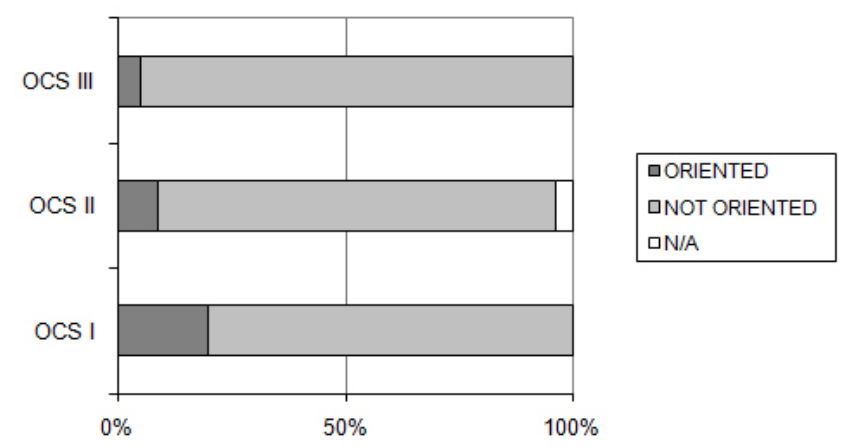

\subsubsection{Exits that Were Used to Evacuate the Building}

Each building had a different number of exits. The percentages of the use of main exits and alternative exits are illustrated for each building in Figure 7. Percentages of use of main exits were found to be $92 \%, 51 \%$ and $70 \%$, respectively for the three cases (OCS1, OCS2 and OCS3), which are significantly higher than the percentage of use of alternative exits for all three cases. The main exit was the door that was routinely used in everyday life for entrance and exit in OCS1 and OCS3. The OCS2 building was a larger building and it had two doors routinely used for entrance and exit in everyday life.

Figure 7. Use of exits.

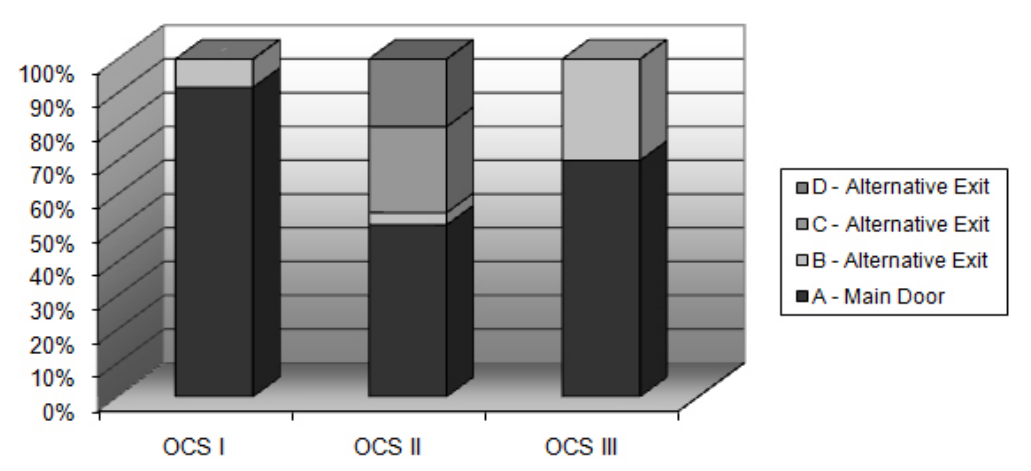




\subsubsection{Use of Unfamiliar Exits}

The location of each respondent was marked on the building plan and the ratio of the distance to the nearest unfamiliar to familiar main exit $(\mathrm{dU} / \mathrm{dF})$ was calculated for each respondent. Figure 8 provides the graphical representation of the findings, showing the percentage likelihood of using unfamiliar exits in OCS2 and OCS3. It is clear from the graph that the use of unfamiliar exit decreases as the ratio of distance to unfamiliar door to the distance to the familiar door increases. In other words, it is more likely for one to choose the unfamiliar door if (s)he is standing closer to it. This also means that if one is equidistant to familiar and unfamiliar door, it is more likely for him/her to choose the familiar door.

This graph does not include OCS1 because the case was not applicable since the unfamiliar doors were not used to evacuate the building except for two people. All the occupants preferred to use the main door, the familiar door that they always used to enter and leave the building in their daily routine although some of them were closer to the other alternative exits.

Figure 8. Percentage likelihood of using unfamiliar exit.

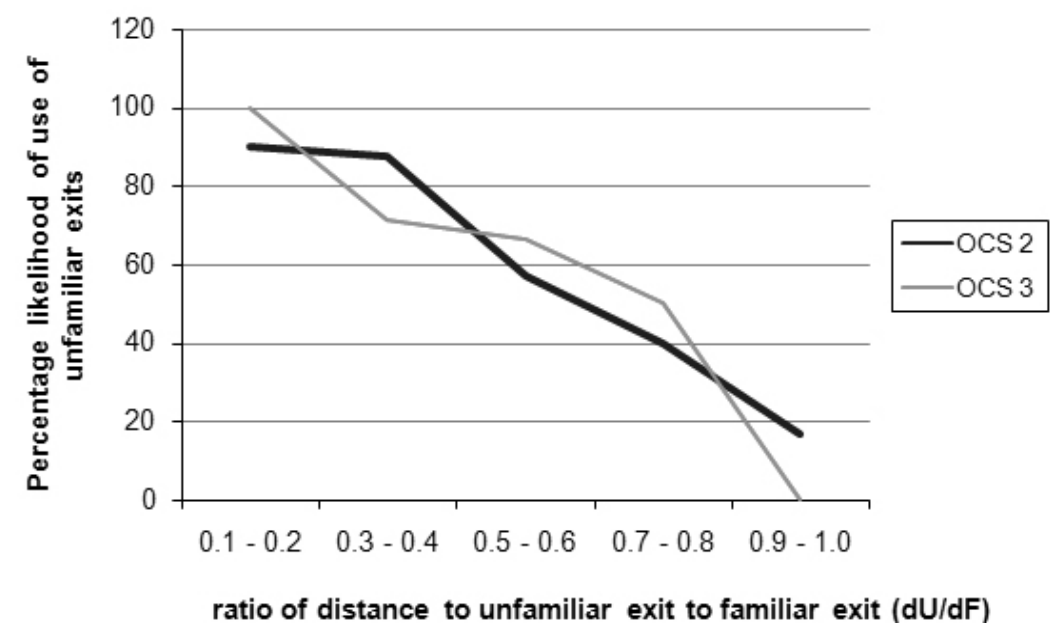

\subsubsection{Reasons for Exit Preferences}

Figure 9 includes the list of reasons for exit preferences listed in the questionnaire and illustrates the percentages for each OCS. The results of the questionnaires revealed that the "perceived distance" or proximity to the exit was the main factor affecting exit preference in all three cases $(27 \%, 48 \%$, and $57 \%)$.

The other two most important factors for OCS1, OCS2 and OCS3, respectively are: "following other people" $(26 \%, 16 \%, 14 \%)$ and "familiarity" $(9 \%, 13 \%, 18 \%)$.

"Following emergency signs" and "visibility" factors were the next most important factors. The percentages for the other factors in the list are very low. "Crowding in front of the doors", "obstacles" and "orientation by the marshals" were not even chosen as a reason for exit preference by any respondent in OCS III. A few "other reasons" which were not listed in the questionnaire were indicated by some of the respondents as "external view" through the glass surface on one of the doors, knowing a "locked door" from previous experience, and "need to get goods/coats/etc." before leaving. 
Figure 9. Reasons for exit preferences.
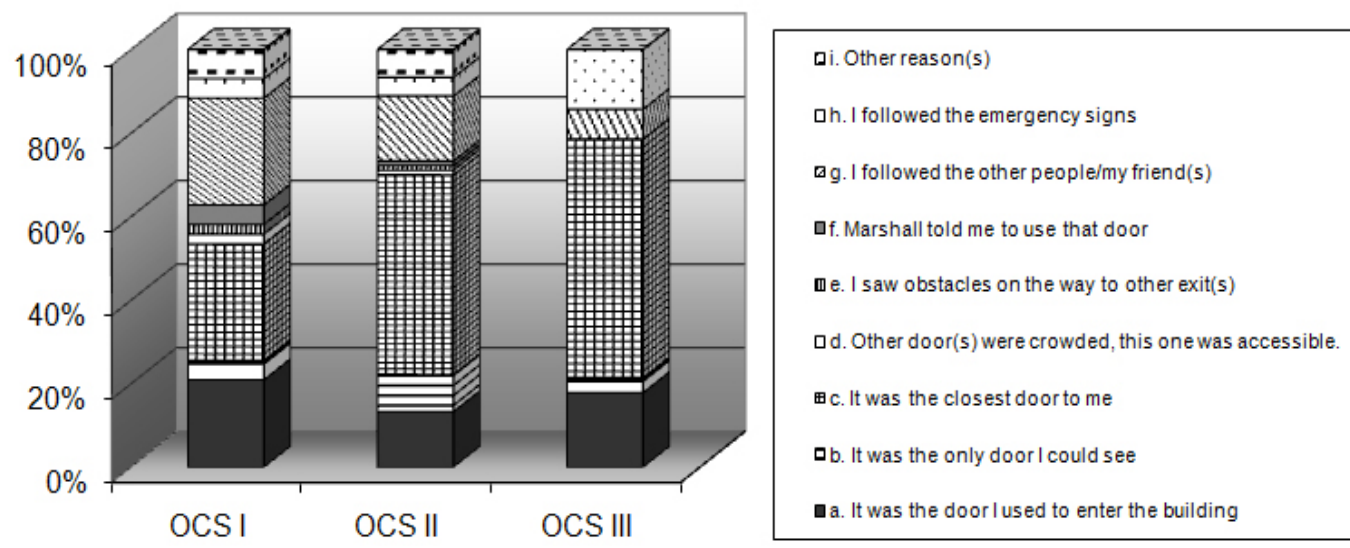

\subsubsection{Bottleneck Problems}

There was a significant bottleneck problem in OCS1 where almost all occupants preferred to use the main door to evacuate the building. Thirty-two percent of the respondents indicated that they faced a bottleneck which occurred at the staircase that was connected to the main door. The office area that was used for OCS1 was located on the first floor. The bottleneck problem was exacerbated when the people from the ground floor started to join the evacuee queue flowing down from the OCS area.

In OCS2, 23\% of the respondents indicated that they faced a bottleneck at the bottom of the staircase leading to the main door (Figure 10).

There was no significant bottleneck problem in OCS3. Only $7 \%$ of the respondents indicated that there was a bottleneck in front of one of the alternative exits located at the rear of the building during the evacuation process.

Figure 10. Bottleneck in the Buro Happold Leeds Office.

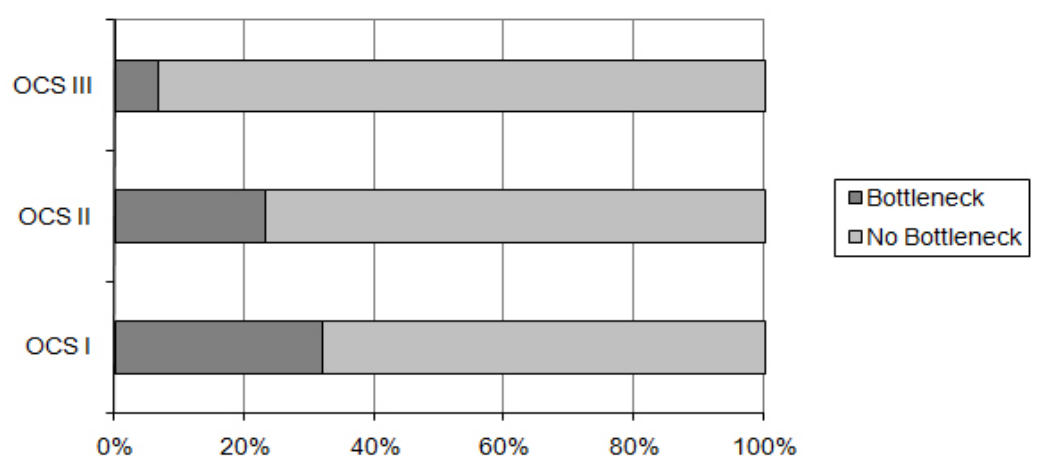

\subsection{Logistic Regression Analysis}

In addition to the percentage calculations of the data collected from the questionnaires, Logistic Regression Analysis was used to build a statistical model of the exit preferences of building occupants using the distance data and the factors identified in the questionnaire. Logistic regression is a statistical analysis approach which is used to analyse the data to predict a non-quantitative (categorical) variable from a set of independent variables. The principle of the logistic regression model is to link the occurrence or non-occurrence of an event to independent variables [22]. The non-quantitative data 
(such as yes/no, male/female, accepting/not accepting) is defined by assigning 0-1 as positive and negative values. For example, in this case, one of the independent variables is not quantitative, "being familiar to exit doors", and it is coded as 1 and "not being familiar with the exits" is coded as 0 . The objective was to find out the "likelihood of choosing (familiar) main doors" during evacuations. In a similar manner, 1 is assigned for "preferring familiar door", and 0 is assigned for "not preferring familiar exit" for the dependent variable. The probabilities can be defined in terms of:

$$
\begin{gathered}
p \quad \text { the probability of choosing the (familiar) main door; } \\
1-p \quad \text { the probability of not choosing the (familiar) main door. }
\end{gathered}
$$$$
\text { (probability of choosing an alternative door) }
$$

The equation of the model would be as below, where $Y$ represents the independent variables, and $x$ represents the constant value for each variable.

$$
\operatorname{Ln}(\mathrm{ODDS})=\mathrm{eta}=x_{0}+x_{1} Y_{1}+x_{2} Y_{2}+\ldots+x_{\mathrm{n}} Y_{\mathrm{n}}
$$

Then, the equation in this case would be:

$$
\text { eta }=x_{1}+x_{2} R+x_{3} F+x_{3} F D+x_{3} F O+x_{3} O
$$

where $R=\mathrm{dU} / \mathrm{dF}$ (ratio of distance to the unfamiliar door to the distance to the familiar door); $F=$ familiarity; $F D=$ perceived distance; $F O=$ following other people; $O=$ other.

The model can be used to predict the odds that a subject will choose the main exit with given familiarity factor by the following formula:

$$
\mathrm{ODDS}_{1}=\operatorname{Exp}(\text { eta })=\mathrm{e}^{x 0+x 1 Y 1+x 2 Y 2+\ldots+x \mathrm{n} Y \mathrm{n}}
$$

Finally, the following equation is used to convert the ODDS to probabilities:

$$
p=\exp (\text { eta }) /(1+\exp (\text { eta }))
$$

The results of the logistic regression analysis conducted in SPSS for the three cases supported the findings from the questionnaires explained above in Section 4.1, as well as previous findings from the pilot case studies. The two variables that are significantly important to build the statistical model were found to be the "ratio of the distance to unfamiliar exit to distance to familiar exit" $(R)$ and the "familiarity with the exits" $(F)$. First, the analysis was conducted using all the factors that were listed in the questionnaires. However, the outputs of the logistic regression analysis showed that all factors are not significantly important. The factors associated with "perceived distance", "following other people", "visibility of the doors", "crowd in front of the door", "emergency signs", "obstacles" and "orientation by the marshals" are not found to be significant at the $90 \%$ or higher confidence level in the logistic regression analysis ( $p$ greater or equal to 0.10 ). Therefore, a second analysis was conducted by removing these variables from the analysis data input set and the equation was simplified as:

$$
\text { eta }=x_{1}+x_{2} R+x_{3} F
$$

The output of this final logistic regression analysis shows the results of fitting a logistic regression model to describe the relationship between exit preference and the two independent variables: distance ratio and familiarity. The equations of the fitted models for the three cases were found to be: 


$$
\begin{gathered}
\text { OCS } 1: \text { eta }=1.45599+1.52012 \times R-2.73862 \times F \\
\text { OCS2: eta }=2.70009+4.41501 \times R-6.41942 \times F \\
\text { OCS3: eta }=-4.27446+8.61295 \times R+0.451994 \times F
\end{gathered}
$$

These equations mean that when the familiarity level and the ratio are substituted in the ratio, the equations will give the likelihood of choosing the familiar door. Familiarity as a qualitative independent variable is coded by 1 and 0 as familiar and unfamiliar. For instance, if one is familiar with the exits (coded as 1) and (s)he is standing closer to the unfamiliar exit (at a 1/2 ratio of distance to unfamiliar/distance to familiar) in OCS1, (s)he is 0.59 as likely to decide to choose the familiar main door and there is a $37 \%$ probability that people will decide to use the main door, as derived from the equations below:

$$
\begin{gathered}
\text { eta }=1.45599+1.52012 \times(0.5)-2.73862 \times 1 \\
\text { ODDS }=\operatorname{Exp}(\text { eta })=\mathrm{e}^{1.45599+1.52012 \times(0.5)-2.73862 \times 1}=0.59 \\
p=\exp (\text { eta }) /(1+\exp (\text { eta }))=0.59 / 1+0.59=0.37
\end{gathered}
$$

With a similar approach, the probability to choose the familiar door is $18 \%$ in OCS2 and $62 \%$ in OCS3. The average of the probability results obtained from various case studies can give an average result for different $R$ and familiarity levels. Table 1 illustrates the results and averages for different standing points for the three case studies in this research.

Table 2 illustrates Analysis of Deviance results for the three OCS. Because the $p$-values for the models are less than 0.01 in all three cases, there is a statistically significant relationship between the variables at the $99 \%$ confidence level in all cases. In addition, the $p$-values for the residuals are greater than 0.10 , indicating that the models are not significantly worse than the best possible model for the data at the $90 \%$ or higher confidence level.

In determining whether the model can be simplified, the highest $p$-value for the likelihood ratio tests was observed. It is found to be 0.0009 , belonging to ratio of distance to unfamiliar to the distance

\begin{tabular}{|c|c|c|c|c|c|}
\hline $\begin{array}{c}\text { Familiarity with } \\
\text { the exits }(F) . \\
1=\text { familiar; } \\
0=\text { unfamiliar }\end{array}$ & $\begin{array}{c}\text { Distance } \\
\text { ratios }(R) \\
\mathbf{d U} / \mathbf{d F}\end{array}$ & $\begin{array}{l}\text { CASE STUDY I } \\
\text { Research Hub }\end{array}$ & $\begin{array}{c}\text { CASE STUDY II } \\
\text { BH Leeds }\end{array}$ & $\begin{array}{c}\text { CASE STUDY III } \\
\text { BH Glasgow }\end{array}$ & Average \\
\hline 1 & $1 / 2$ & 37 & 18 & 62 & $39 \%$ \\
\hline 1 & $1 / 1$ & 56 & 68 & 99 & $74 \%$ \\
\hline 1 & $2 / 1$ & 85 & 99 & 100 & $95 \%$ \\
\hline 0 & $1 / 2$ & 90 & 99 & 51 & $80 \%$ \\
\hline 0 & $1 / 1$ & 95 & 100 & 99 & $98 \%$ \\
\hline 0 & $2 / 1$ & 99 & 100 & 100 & $97 \%$ \\
\hline
\end{tabular}
to familiar exit $(R)$ in OCS1, 0.0005 belonging to familiarity $(F)$ in OCS2 and 0.0159 again belonging to familiarity $(F)$ in OCS3 (Table 3). Because the $p$-values are less than 0.01 in all cases, these variables are statistically significant at the $99 \%$ confidence level and there is no need to remove any variables from the model.

Table 1. Sample findings for different standing points and level of familiarity. 
Table 2. Analysis of deviance.

\begin{tabular}{|c|c|c|c|c|c|c|c|c|c|}
\hline \multirow{2}{*}{ Source } & \multicolumn{3}{|c|}{ OCS I } & \multicolumn{3}{|c|}{ OCS II } & \multicolumn{3}{|c|}{ OCS III } \\
\hline & Deviance & Df & $p$-value & Deviance & Df & $p$-value & Deviance & Df & $p$-value \\
\hline Model & 20.8457 & 2 & 0.0000 & 55.9578 & 2 & 0.0000 & 14.8426 & 2 & 0.0006 \\
\hline Residual & 70.0231 & 75 & 0.6409 & 18.828 & 51 & 1.0000 & 12.0779 & 17 & 0.7954 \\
\hline Total (corr.) & 90.8688 & 77 & & 74.7858 & 53 & & 26.9205 & 19 & \\
\hline
\end{tabular}

Table 3. Likelihood ratio test.

\begin{tabular}{|c|c|c|c|c|c|c|c|c|c|}
\hline \multirow{2}{*}{ Source } & \multicolumn{3}{|c|}{ OCS I } & \multicolumn{3}{|c|}{ OCS II } & \multicolumn{3}{|c|}{ OCS III } \\
\hline & Chi-square & Df & $p$-value & Chi-square & Df & $p$-value & Chi-square & Df & $p$-value \\
\hline$R$ & 11.1095 & 1 & 0.0009 & 34.6392 & 1 & 0.0000 & 14.8426 & 1 & 0.0001 \\
\hline$F$ & 11.62 .97 & 1 & 0.0006 & 11.9639 & 1 & 0.0005 & 5.81548 & 1 & 0.00159 \\
\hline
\end{tabular}

The Chi-square Goodness of Fit Test determines whether the logistic function adequately fits the observed data. The $p$-value for the three cases was found to be $0.1982826,0.132819$, and 0.515845 respectively. There is no reason to reject the adequacy of the fitted model at the $90 \%$ or higher confidence level because the $p$-values are greater than 0.10 .

\subsection{Findings from the Simulation Case Studies}

The three observed buildings were modelled in building EXODUS to conduct simulations of the three evacuation scenarios explained in Section 3.2.2 where the use of familiar and unfamiliar doors differs. Figure 11 illustrates the 2D representation of the model of the second case study building. All three simulations were conducted with the same number of people and the following occupant characteristics were assigned in the simulations based on the office occupant characteristics defined in PD7974 "The application of fire safety engineering principles to fire safety design of buildings: Part 6":

- The response time after the emergency alarm was identified as 30-90 s;

- Fast walk speed was identified as $1.2 \mathrm{~m} / \mathrm{c}$;

- Stair down speed was identified as $0.8 \mathrm{~m} / \mathrm{s}$.

The results of the three simulations for each building are presented in Table 4. In Scenario 1, the main door was blocked to eliminate the familiarity factor in exit use. In Scenario 2, the assumption made by the current building guidance was simulated where there is an equally balanced use of all available exits during an evacuation test (PD7974, 2004). Scenario 3 simulates the user behavior in a real evacuation test conducted in the OCS1, which was an extreme case where all building occupants preferred to use the familiar (main) door to evacuate the building, ignoring the other alternative exits. The difference in evacuation times of Scenarios 1 and 2 is not significant with a few seconds change for all three buildings. However, the difference in evacuation times of Scenarios 2 and 3 are high in all three cases $(21 \mathrm{~s}, 19 \mathrm{~s}, 40 \mathrm{~s})$ demonstrating that the evacuation time can increase $20 \%-21 \%$ if there is not an equally balanced use of exits. 
Figure 11. Case study II model in 2D.

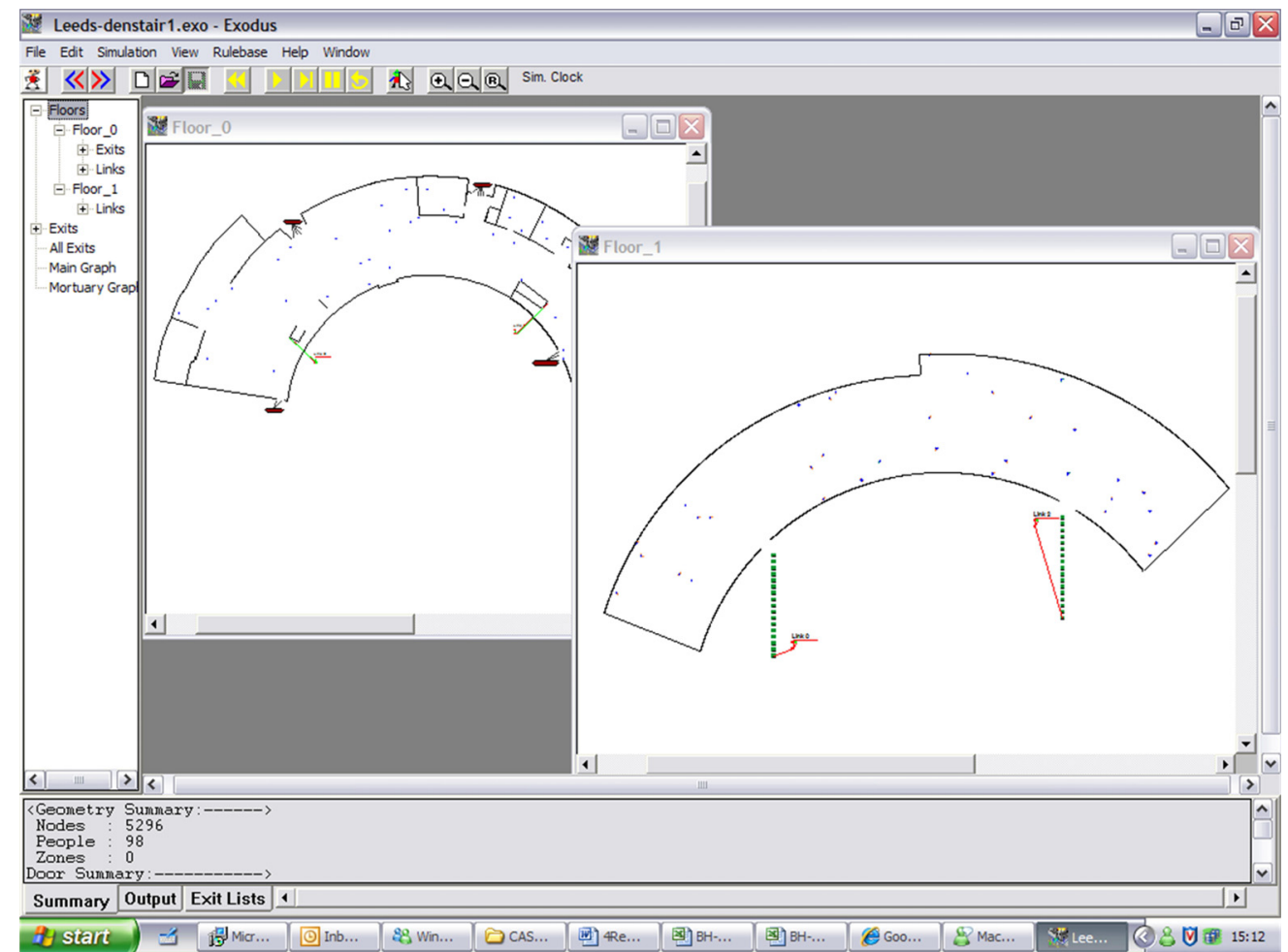

Table 4. Evacuation times for each simulation scenario.

\begin{tabular}{ccccc}
\hline Buildings & $\begin{array}{c}\text { Scenario 1 } \\
\text { (Main door blocked, all } \\
\text { occupants use the } \\
\text { alternative nearest exit) }\end{array}$ & $\begin{array}{c}\text { Scenario 2 } \\
\text { (All exits are open and } \\
\text { there is an equally } \\
\text { balanced use of exits) }\end{array}$ & $\begin{array}{c}\text { Scenario 3 } \\
\text { (All occupants } \\
\text { use only the } \\
\text { main door) }\end{array}$ & $\begin{array}{c}\text { Increase } \\
\text { (Scenario 2 to } \\
\text { Scenario 3) }\end{array}$ \\
\hline Building I & $109 \mathrm{~s}$ & $107 \mathrm{~s}$ & $128 \mathrm{~s}$ & $21 \%$ \\
Building II & $110 \mathrm{~s}$ & $109 \mathrm{~s}$ & $128 \mathrm{~s}$ & $20 \%$ \\
Building III & $195 \mathrm{~s}$ & $192 \mathrm{~s}$ & $232 \mathrm{~s}$ & $21 \%$ \\
\hline
\end{tabular}

These results highlight that the assumption of equally balanced use of exits in current building guidance can lead to insufficient and unsafe designs that consider incorrectly predicted evacuation times.

\subsection{Evaluation of the Results}

Efficient design of the evacuation routes and exits can help to decrease the evacuation time by providing clear and short routes and by minimizing the bottlenecks. In this way, we can increase the number of people saved in extreme events. Performance of evacuation is highly dependent on the behavior and preferences of occupants during the emergency event. Within this context, the study started with the identification of the factors affecting the exit preferences of people during emergency events via literature review and OCS. It was found that the exit preferences of people are influenced by various factors related to interactions of people with other people and their immediate environment. The results of the OCS showed that:

- There is not an equally balanced use of exit doors during emergency evacuations; 
- The two factors that are most important in exit preference are "distance" and "familiarity" with the exits;

- The likelihood of use of familiar exits decreases as the ratio of distance to unfamiliar exit to familiar exit increase, in other words, people are more likely to use the unfamiliar exit if they are standing close to it;

- If one is standing equidistant to familiar and unfamiliar exit, it is more likely for him/her to choose the familiar door.

The logistic regression analysis, which was conducted to build a statistical model identified "familiarity" and "distance" as the most important factors affecting the exit preferences in all the case studies. The other factors such as "perceived distance", "following other people", "visibility of the doors", "crowd in front of the door", "emergency signs", "obstacles" and "orientation by the marshals" are not found to be particularly important in the analysis due to the characteristics of the participants and building use. The visual space and perceived space are different concepts. Perceived distance for each person in space can change with many factors such as geometry and obstacles on the way when compared with the measured real distance especially when we consider exit preference for large public buildings where all occupants are not familiar with the building. However, in our cases, the buildings were not very large and all the participants in the evacuation drills were everyday users of the buildings, so they all already knew the location of all exit doors, and they all had an idea and experience in terms of perceived distance to all exit doors from wherever they stand. This is the reason why perceived distance, visibility and signage were not particularly important in exit preference. Pauls [23] also stated that population characteristics and routine building use should be considered in the design of means of egress.

The three logistic regression model equations presented the odds and probabilities for each case. Ratio of distance to unfamiliar door to the distance to familiar door $(R)$ was used to define the distance factor. Substitution of various familiarity level and $\mathrm{R}$ input gave the percentage of evacuees that would use the familiar exit. It was observed that the average of the probability of choosing the main familiar door increases at points closer to the familiar exits (Table 1).

In this study, all the buildings were open plan office buildings with one or two levels. It is possible to get more reliable average results by conducting the logistic regression analysis for a greater number of case studies. Moreover, it is possible to obtain more specific results for different building types with different functions (schools, shopping centers, schools, etc.), different geometries (circular, rectangular, etc.), different size of buildings (buildings with 1-2 levels, high rise buildings, etc.), or for any other classifications. These classified results obtained from various case studies can be a guide to architects and designers, enabling them to compare the possible outcomes from their design solutions. The evacuation modeling software can be a useful tool to test their own design solutions to achieve the best working solution to increase safety in the building, during the building design process.

Within this context, the research continued with SCS to identify how exit preference can change the evacuation time based on familiarity factor. Three scenarios were simulated using the evacuation modeling software building EXODUS and the evacuation times were compared for the cases of equally balanced and unbalanced use of exits. The people were oriented to the nearest exits in evacuation modeling simulations to achieve equally balanced use of exits and to other door(s) by 
blocking doors. The blocked door(s) in the simulations represent the unused door(s) which may be a result of a hazard, fire and/or obstruction near the door(s), or personal rejection in real life. The findings from SCS emphasized that:

- The evacuation time in case of imbalanced use of exits is hugely different from the case of equally balanced use of exits, which was assumed in the current building guidance;

- The average increase in evacuation time for imbalanced use of exits compared to the equally balanced use of exits was found to be $20 \%$.

This fact is not considered in the current building codes, standards and guidelines although awareness and control of the evacuation time is vital. The assumption of equally balanced use of exits in current building guidance can lead to insufficient and unsafe designs that consider incorrectly predicted evacuation times.

\section{Conclusions and Further Research}

This study is a contribution to the ongoing efforts on mitigating the impacts of extreme events such as terrorist attacks. The research is an investigation of safe building design to improve current building guidance. The paper summarized the literature review on building design issues relative to people's behavior and exit preferences during building evacuations. Logistic regression analysis was used to develop an approach to find probabilities for exit preference under different circumstances based on distance and familiarity. Then, case study buildings were modeled and various evacuation scenarios were simulated to test how the use of a different number of exits would change the evacuation time using the evacuation modeling software building EXODUS. The results of this research highlight the following:

- Factors other than "distance" and "familiarity with the exits" (such as emergency signs, visibility, following other people), were not found to be significant in the statistical analysis;

- There is not an equally balanced use of exits during the evacuation process;

- The imbalanced use of exits increases the evacuation time;

- There is a need to revise the current building design guidance to encourage designers to use dynamic information based on user behavior in emergency situations.

The findings of this research can be of immense benefit to architects, designers, engineers, construction experts and regulatory bodies in ensuring increased awareness of the lack of knowledge on emergencies and dynamic information, and defining deficiencies and failures in current standards or the development of new ones.

The results of this research can also help modeling and simulation researchers and developers in expanding developments in evacuation modeling and simulation tools based on the definition of new requirements in the application area covered by this research. The computer is a significant and functional tool for the simulation of people movement and interactions [7]. These simulations have the potential to help in testing design solutions, in order to better control fatalities in the built environment and create safer built environments.

Various solutions in ingress and egress design (such as providing sufficient number and location of doors, orienting people in circulation with building design, attractive exit doors or designing a solution 
to familiarize building occupants with the building and exit doors) can be tested in further research studies to decrease evacuation time and facilitate and enhance safety and security during evacuation. In this research, less than $70 \%$ of the number of participants responded to the questionnaire in observation case studies. A more quantitative approach is needed to capture and integrate dynamic information in design process with more observation-based case studies and research to keep design information up-to-date within changing circumstances in people and their environment. The findings of this research can be supported via more evacuation case studies with quantified approaches to produce proposals for developing new and/or revising current building design guidelines. Moreover, other building design issues that conflict with real life situations need to be identified in current building guidelines in order to design and conduct further research to capture dynamic information that can guide the designers, architects and engineers in emergency design.

\section{Conflict of Interest}

The authors declare no conflict of interest.

\section{References}

1. Geis, D.F. By design: The disaster resistant and quality-of-life community. Nat. Hazards Rev. 2000, 1, 151-160.

2. Kecklund, L.; Andrée, K.; Bengtson, S.; Willander, S.; Siré, E. How do people with disabilities consider fire safety and evacuation possibilities in historical buildings?-A Swedish case study. Fire Technol. 2012, 48, 27-41.

3. Koo, J.; Kim, Y.; Kim, B.; Christensen, K. A comparative study of evacuation strategies for people with disabilities in high-rise building evacuation. Exp. Syst. Appl. 2013, 40, 408-417.

4. Akadiri, P.O.; Chinyio, E.A.; Olomolaiye, P.O. Design of a sustainable building: A conceptual framework for implementing sustainability in the building sector. Buildings 2012, 2, 126-152.

5. Brocklehurst, D.; Bouchlaghem, D.; Pitfield, D.; Green, M.; Still, K. Design and space planning for secondary schools: Considerations for circulation modelling. ICE Struct. Build. J. 2006, Record number: 000019293.

6. Brocklehurst, D.; Palmer, G.; Bouchlaghem, D.; Pitfield, D.E.; Still, K. Crowd circulation and stadium design: Low flow rate systems. ICE Struct. Build. J. 2005, 158, 281-289.

7. Langston, P.A.; Masling, R.; Asmar, B.N. Crowd dynamics discrete element multi-circle model. Saf. Sci. 2006, 44, 395-417.

8. Hale, A.; Kirwan, B.; Kjellén, U. Safe by design: Where are we now? Saf. Sci. 2007, 45, 305-327.

9. Chu, J.; Yeh, C.Y. Emergency evacuation guidance design for complex building geometries. J. Infrastruct. Syst. 2012, 18, 288-296.

10. Glover, N.J. Design versus disaster. J. Archit. Eng. 2000, 6, 77-78.

11. Fruin, J.J. The Causes and Prevention of Crowd Disasters. In Proceedings of the First International Conference on Engineering for Crowd Safety, London, UK, 17-18 March 1993.

12. Nguyen, Q.H.; McKenzie, F.D.; Petty, M.D. Crowd Behavior Cognitive Model Architecture Design. In Proceedings of the 2005 Conference on Behavior Representation in Modeling and Simulation (BRIMS), Anaheim, CA, USA, 16-19 May 2005; pp. 55-64. 
13. Kuligowski, E. Predicting human behavior during fires. Fire Technol. 2013, 49, 101-120.

14. Provitolo, D.; Dubos-Paillard, E.; Muller, J.P. Emergent Human Behaviour During A Disaster: Thematic Versus Complex Systems Approaches. In Proceedings of EPNACS 2011 within ECCS'11 Emergent Properties in Natural and Artificial Complex Systems, Vienna, Austria, 15 September 2011; pp. 47-57.

15. Fruin, J.J. Crowd Dynamics and Auditorium Management. Auditorium News, International Association of Auditorium Managers, May 1984. Available online: http://www.iaamweb.org/ cvms/IAAMCrowdDyn.doc (accessed on 1 May 2013).

16. Benthorn, L.; Frantzich, H. Fire alarm in a public building: How do people evaluate information and choose an evacuation exit? Fire Mater. 1999, 23, 311-315.

17. Gwynne, S.; Galea, E.R.; Lawrence, P.J.; Filippid, L. Modelling occupant interaction with reconditions using the building EXODUS evacuation model. Fire Saf. J. 2001, 36, 327-357.

18. Kuligowski, E.D. The Evaluation of a Performance-Based Design Process for a Hotel Building: The Comparison of Two Egress Models. Master Thesis, Department of Fire Protection Engineering, Faculty of the Graduate School of the University of Maryland, College Park, MD, USA, December 2003.

19. Shen, T.S. Building Planning Evaluations for Emergency Evacuation. Ph.D. Thesis, Worcester Polytechnic Institute, Worcester, MA, USA, December 2003.

20. Exodus Website, 2008. Available online: http://fseg.gre.ac.uk/exodus (accessed on 1 May 2013).

21. Galea, E.R.; Gwyne, S.; Lawrence, P.J.; Filippidis, L.; Blackshields, D. Building EXODUS V4.0 User Guide and Technical Manual; Fire Safety Engineering Group, University of Greenwich, Greenwich, UK, 2004.

22. Menard, S.W. Applied Logistic Regression Analysis; SAGE Publications: London, UK, 2001.

23. Pauls, J. The movement of people in buildings and design solutions for means of egress. Fire Technol. 1984, 20, 27.

(C) 2013 by the authors; licensee MDPI, Basel, Switzerland. This article is an open access article distributed under the terms and conditions of the Creative Commons Attribution license (http://creativecommons.org/licenses/by/3.0/). 